\title{
Histopathological Analysis of Ovarian Tumours -Analysis of 2 Years
}

\author{
Author \\ Dr Sujeet Kumar Mandal, MD Pathology \\ Assistant Professor, Dept. of Pathology \\ Jawaharlal Nehru Medical College, Bhagalpur, Bihar INDIA
}

\begin{abstract}
Background: Ovarian tumours are one of the most prevalent gynaecological tumours in females. They often present in mid-decade of life insidiously. Ovarian cancer is the most frequent cause of death from gynaecological cancers.

Aims and Objectives: To study histological pattern of Ovarian Tumours in Bihar

Material and Methods: Institutional Ethical Committee approval and written informed consent from patients were taken. Ovarian specimens of 145 patients with suspected ovarian mass were studied for histopathological examination during the period of October 2012 to October 2014.

Results: Mean age of cases was $44.3 \pm 9.5$ years. Majority of the cases of ovarian were in age group of 20 - 40 years ( $63.45 \%$ ). Age rage was from 21 years to 69 years. 123 cases ( $84.83 \%$ ) were benign, 3 cases $(2.07 \%)$ were borderline and 19 cases $(13.1 \%)$ were malignant. There were 111 cases $(76.55 \%)$ of surface tumours, 31 cases (21.38\%) germ cell, 1 case ( $0.69 \%)$ of sex cord, 2 cases (1.38\%) of metastatic ovarian tumours. Among benign tumours, there were 96 cases of Serous cyst adenoma ( 66.21\% ), 4 cases of Mature cystic Teratoma , 1 case of Serous cyst adenofibroma (0.69 \% ), 1 case of Teratoma with Struma ovarii $(0.69 \%)$.Among malignant tumours, there were 12 cases $(63.16 \%)$ of Serous cyst adenocarcinoma, 3 cases $(15.79 \%)$ of Immature teratoma , 2 cases of (10.53\%) Mucinoius cyst adenocarcinaoma, 1 case $(5.26 \%)$ of Krukenberg tumour and Granulosa cell tumour each.

Conclusion: Serous cyst adenoma are the most common benign ovarian tumour found in ovarian specimens with peak incidence at $20-50$ years.
\end{abstract}

\section{INTRODUCTION}

Ovarian tumours are one of the most prevalent gynaecological tumours in females. They often present in mid-decade of life insidiously. Occurrenceof these lesions is different according to geographical locations. Ovarian neoplasms, which are sub set of ovarian mass, are common tumours in females comprising $23 \%$ of all gynaecological tumours and are the most common gynaecological malignancy ${ }^{(1)}$. Women between 40 and 60 years of age have ovarian cancer incidence rates 2 to 3 times higher than younger women. Ovarian cancer is the most frequent cause of death from gynaecological cancers and the fourth most frequent cause of death from cancer in women in Europe, United States and Eastern India. Ovarian tumours are notorious for their large size and their frequent association with relatively mild symptoms. it is detected late in the clinical course of the disease. Risk Factors for ovarian cancer are not well defined. However there is general agreement on 
two: nulliparity and family history ${ }^{(2)}$. A higher frequency of carcinoma is seen in unmarried women and in married women with low parity. The lifetime risk of ovarian cancer in women with no family history is $1.6 \%$; with one affected first degree relative is $5 \%$ and $7 \%$ with two or more affected first degree relatives. One of the unique characteristics of ovarian tumors are their capacity to undergo peritoneal metastasis in the absence of invasive growth in the ovary. This has led to the concept of borderline tumors with a strict histologic criteria not influenced by its metastatic counterpart in the peritoneum. They commonly present with abdominal pain, a lump or menstrual irregularities ${ }^{(3,4)}$. In addition to biopsy, various diagnostic modalities include transvaginal ultrasonography, MRI, positron emission tomography and markers like serum CA 125 exists. Due to lack of well established cancer registry in India, changing trends of ovarian tumors has not been determined ${ }^{(5,6)}$.

Diverse histopathologies are common in ovarian lesions. Relative frequency of different ovarian tumors is different for western world and Asian countries. For example surface epithelial tumors account for $50.0-55.0 \%$ of all ovarian tumors and their malignant counterpart for approximately $90.0 \%$ of all ovarian cancers in Western world whereas this figure is $46.0-50.0 \%$ and $70.0-$ $75.0 \%$ respectively in Japan. Similarly mucinous tumors account for $12.0-15.0 \%$ of all ovarian tumors in Western world ${ }^{(7,8)}$. This figure is $20.0-$ $23.0 \%$ for Japan. Germ cell tumors account for $30.0 \%$ of primary ovarian tumors and malignant germ cell tumors account for $3.0 \%$ of all ovarian cancers in Western world. Determination of these patterns is important for diagnosis, management and prognosis ${ }^{(9,10)}$.

\section{AIMS AND OBJECTIVES}

To study the histological pattern of Ovarian Tumours in Bihar

\section{MATERIAL AND METHODS}

We obtained Institutional Ethical Committee approval and written informed consent from patients. Ovarian specimens of 145 patients with suspected ovarian mass were studied for histopathological examination during the period of October 2012 to October 2014.

\section{Method of collection of data:}

The specimens were allowed to fix in $10 \%$ buffered formalin for 24-28 hours. After fixation multiple bits were taken from representative areas of the tumor and the accompanying tissue. Special attention was given to solid areas adjacent to the ovarian surface and papillary projections. They were processed for histopathological examination and paraffin blocks were made. The blocks were cut at 3-5 $\mu \mathrm{m}$ thickness and stained with hematoxylin and eosin stain. Special stains and immunohistochemistry were carried out whenever needed.

\section{Study Period:}

Two year prospective study from October 2012 to October 2014

\section{Inclusion criteria}

1. Clinical and radiological suspicion of ovarian mass

2. Age group within 20 to 70 years

\section{Exclusion criteria}

1. Pregnancy related causes

2. Bleeding Diathesis

\section{Sample size}

Based on previous studies and statistical formula, a sample size of 145 was determined with an alpha error of 0.05 and power of 0.95 .

\section{Statistical methods}

In the statistical analysis of our study, Continuous variables were presented as mean for parametric data and median if the data is non parametric or skewed. Student $t$ test was applied for calculation of statistical significance whenever the data followed normative distribution. Mann whitney test was applied whenever data followed non normative distribution. Categorical variables was expressed as frequencies and percentages. Nominal categorical data between the groups was 


\section{JMSCR VoI||05||Issue||01||Pages 17214-17221||January}

compared using Chi-square test or Fisher's exact test as appropriate. $\mathrm{P}<0.05$ was taken to indicate a statistically significant difference. Minitab version 17 was used for computation of statistics.

\section{RESULTS}

Table.1. Age profile of the study group

\begin{tabular}{|l|c|c|}
\hline AGE & NO. OF CASES & PERCENTAGE \\
\hline $20-30$ & 14 & $9.66 \%$ \\
\hline $30-40$ & 78 & $53.79 \%$ \\
\hline $40-50$ & 28 & $19.31 \%$ \\
\hline $50-60$ & 18 & $12.41 \%$ \\
\hline $60-70$ & 7 & $4.83 \%$ \\
\hline Total & 145 & $100.00 \%$ \\
\hline
\end{tabular}

Diagram . 1. Age profile of the study group

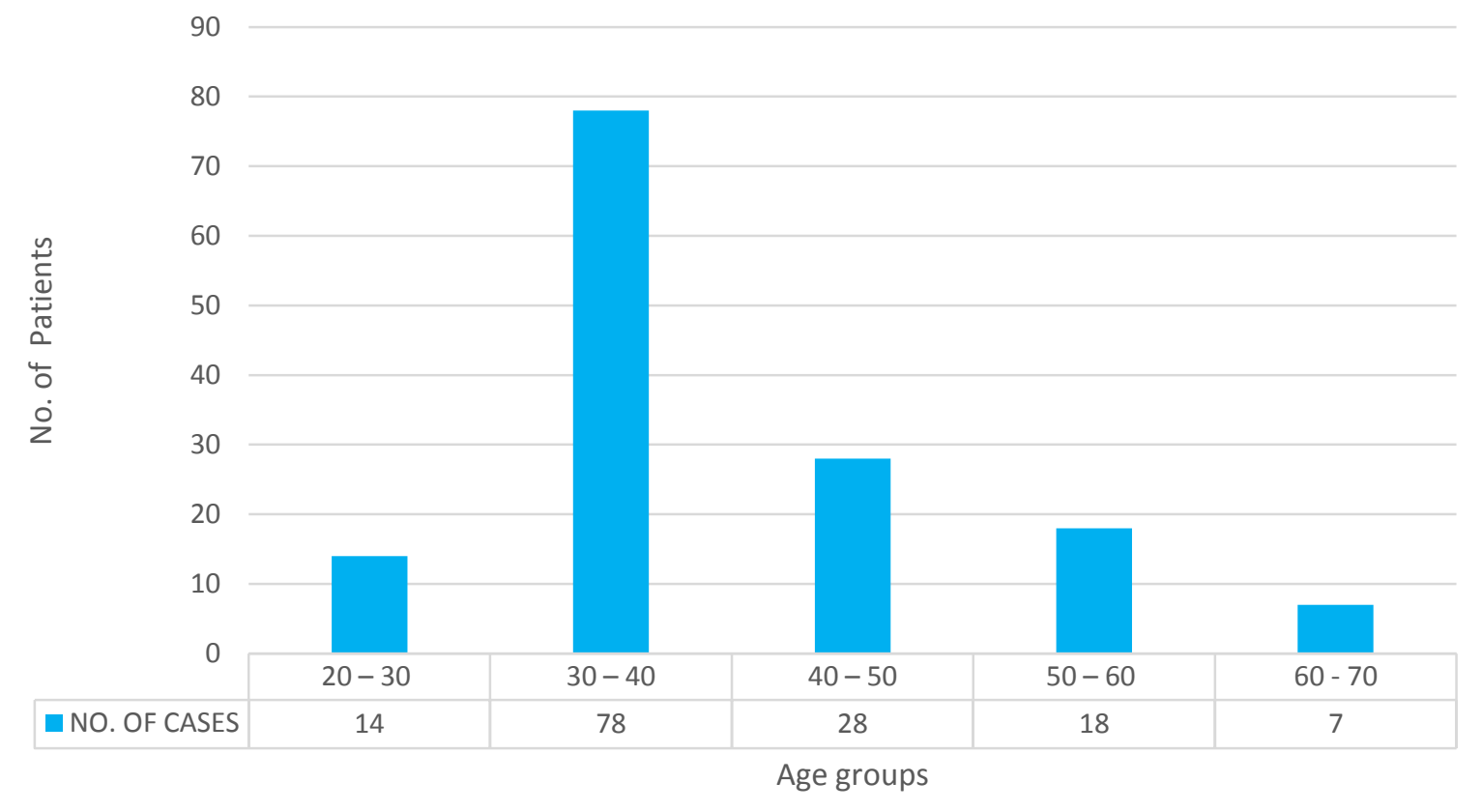

Table.2. Types of Ovarian mass

\begin{tabular}{|l|c|c|}
\hline TYPE & NO. OF CASES & PERCENTAGE \\
\hline BENIGN & 123 & $84.83 \%$ \\
\hline BORDERLINE & 3 & $2.07 \%$ \\
\hline MALIGNANT & 19 & $13.10 \%$ \\
\hline TOTAL & 145 & $100 \%$ \\
\hline
\end{tabular}


Diagram.2. Types of Ovarian mass

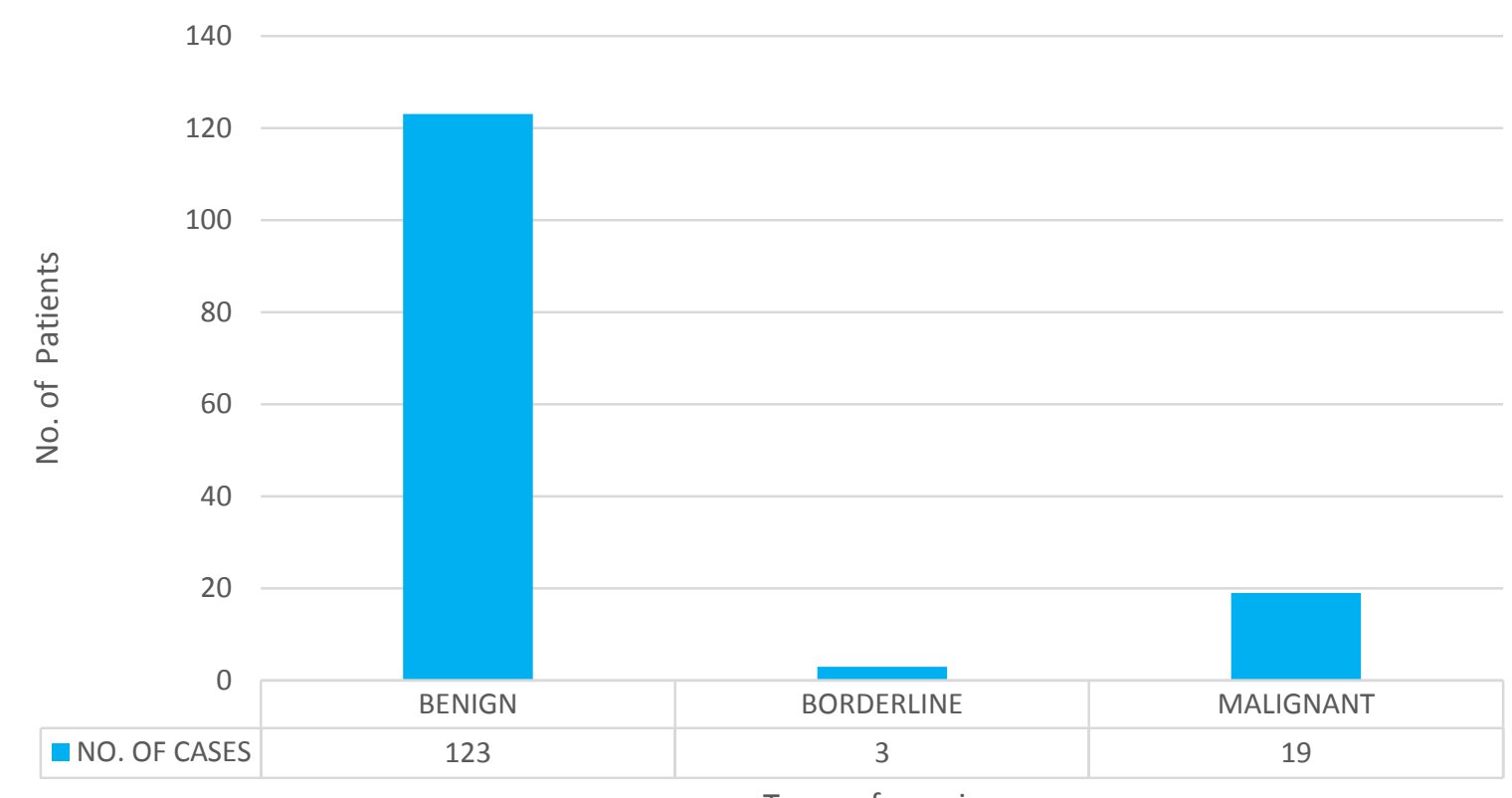

Types of ovarian

Table.3. Types Tumors according to various layers

\begin{tabular}{|l|c|c|}
\hline TYPE & NO. OF CASES & PERCENTAGE \\
\hline Surface & 111 & $76.55 \%$ \\
\hline Germ cell & 31 & $21.38 \%$ \\
\hline Sex cord & 1 & $0.69 \%$ \\
\hline Metastasis & 2 & $1.38 \%$ \\
\hline Total & 145 & $100.00 \%$ \\
\hline
\end{tabular}

Diagram.3. Types Tumors according to various layers

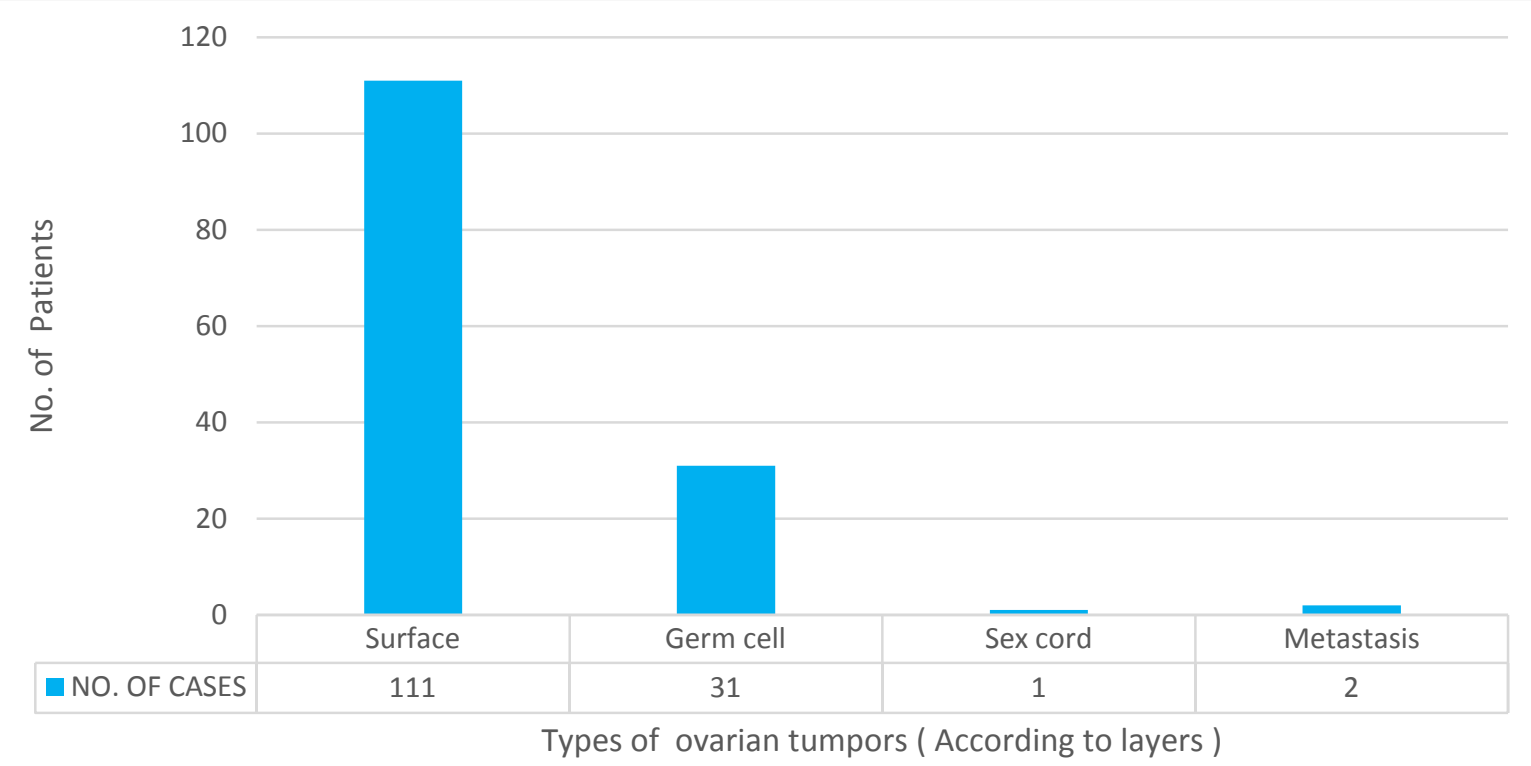


Table.4. Morphological Sub types of Benign tumors of ovary

\begin{tabular}{|l|c|c|}
\hline SUB TYPES & NUMBER & PERCENTAGE \\
\hline Serous cyst adenoma & 96 & $66.21 \%$ \\
\hline Mature cystic Teratoma & 43 & $29.66 \%$ \\
\hline Mucinous cystadenoma & 4 & $2.76 \%$ \\
\hline Serous cyst adenofibroma & 1 & $0.69 \%$ \\
\hline Brenners tumour & 0 & $0.00 \%$ \\
\hline Teratoma with Struma ovarii & 1 & $0.69 \%$ \\
\hline Total & 145 & $100 \%$ \\
\hline
\end{tabular}

Diagram.4. Morphological Sub types of Benign tumors of ovary

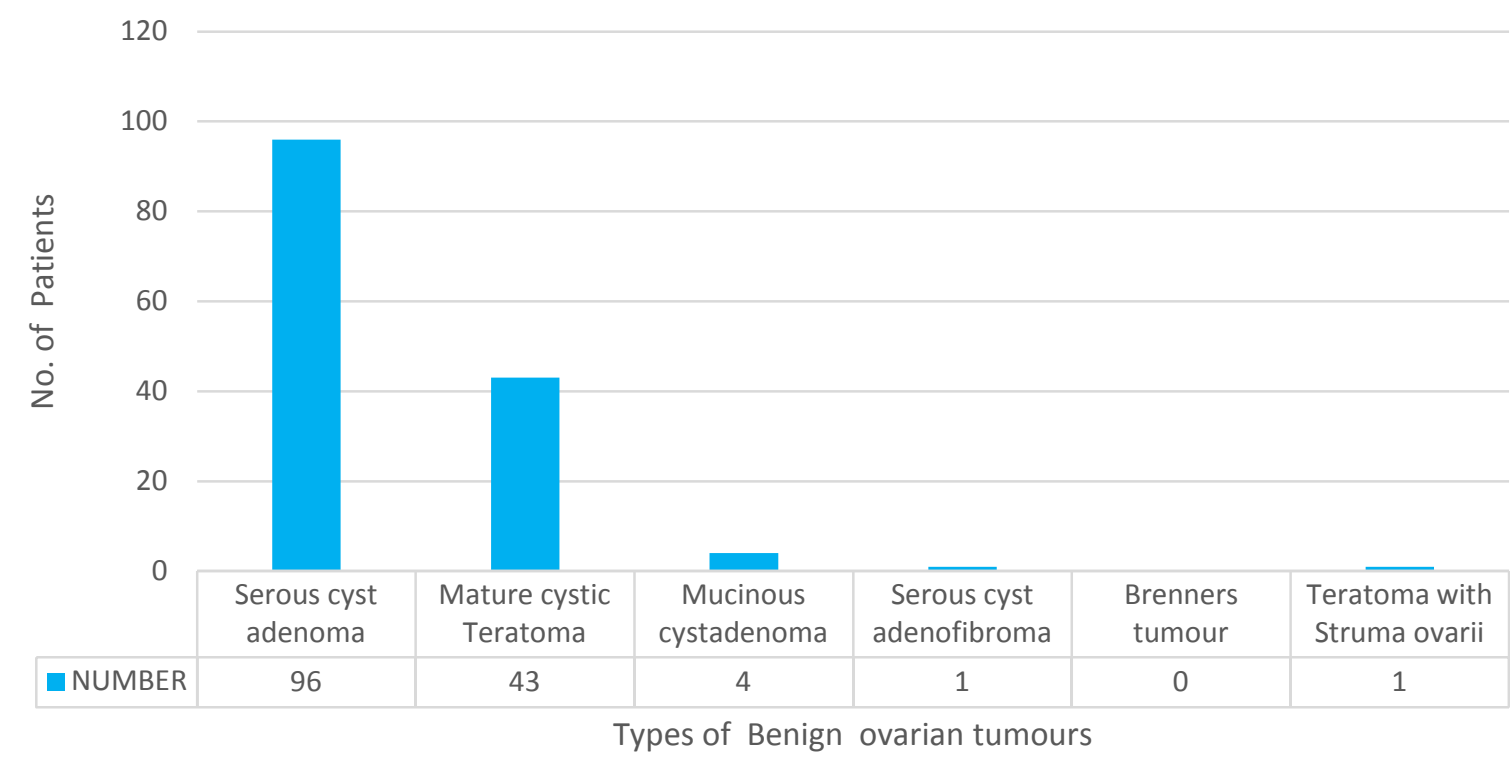

Table 5.Distribution of Malignant Ovarian neoplasm

\begin{tabular}{|l|c|c|}
\hline SUB TYPES & NUMBER & PERCENTAGE \\
\hline Serous cyst adenocarcinoma & 12 & $63.16 \%$ \\
\hline Immature teratoma & 3 & $15.79 \%$ \\
\hline Mucinoius cyst adenocarcinaoma & 2 & $10.53 \%$ \\
\hline Krukenberg tumour & 1 & $5.26 \%$ \\
\hline Dysgerminoma & 0 & $0.00 \%$ \\
\hline Granulosa cell tumour & 1 & $5.26 \%$ \\
\hline Total & 145 & $100 \%$ \\
\hline
\end{tabular}


Diagram 5.Distribution of Malignant Ovarian neoplasm

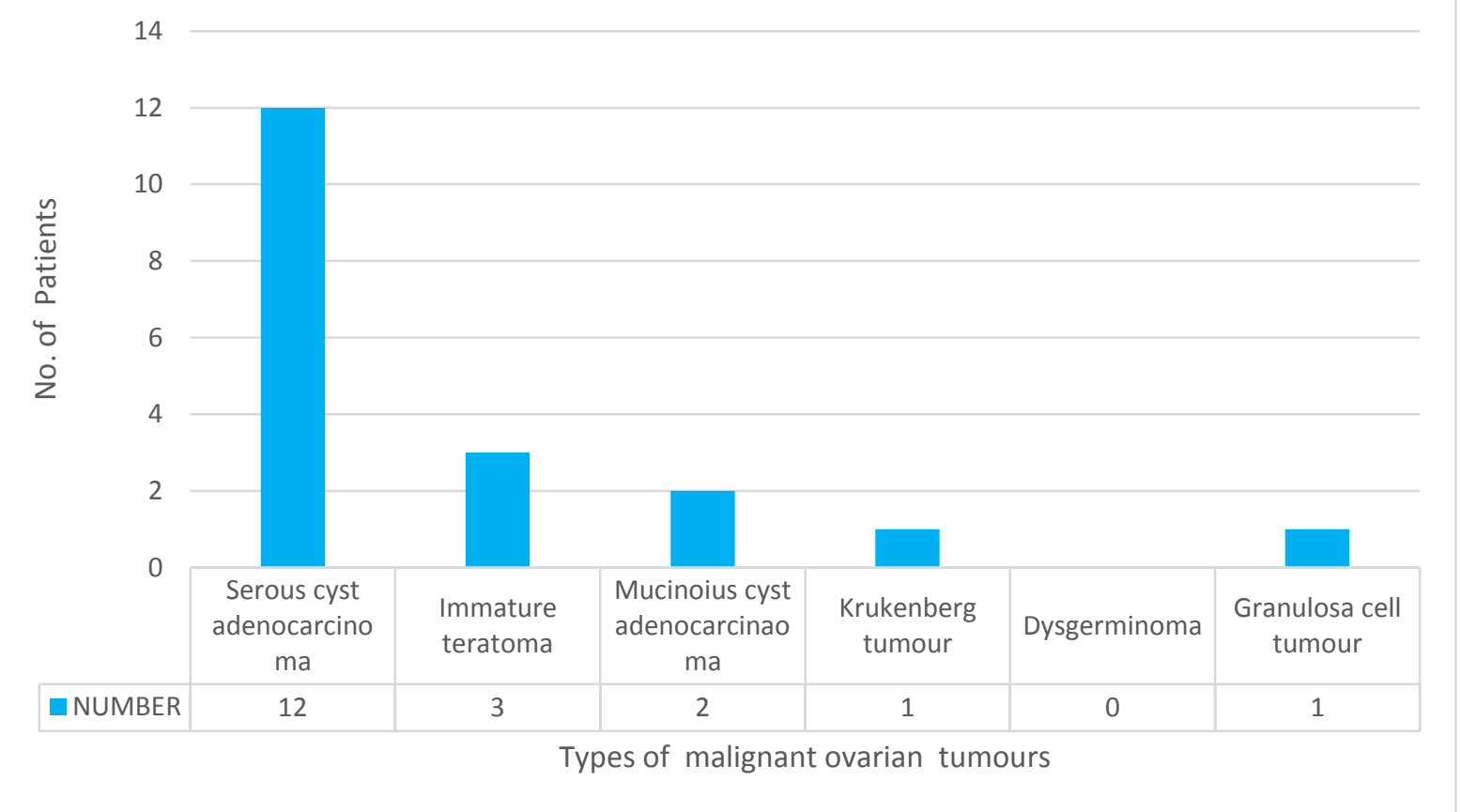

\section{DISCUSSION}

In our study, mean age of cases was $44.3 \pm 9.5$ years. Majority of the cases of ovarian were in age group of $20-40$ years $(63.45 \%)$. Age rage was from 21 years to 69 years. Thus age group of 20 - 50 years seems to be most vulnerable age group for ovarian mass. In study by Shreya Hegde et al , study reported highest no. of cases in $2^{\text {nd }}-$ $5^{\text {th }}$ decade of life ${ }^{(11)}$. In study by Veena Saxena, similar higher incidence was found in $2^{\text {nd }}-5^{\text {th }}$ decade of life. These findings differs from the western data where it higher incidence was between 50 and 70 years.

In our study, 123 cases ( $84.83 \%$ ) were benign , 3 cases $(2.07 \%)$ were borderline and 19 cases (13.1\%) were malignant. In study by Veena Saxena, 98(80.8\%) cases of Benign, 2 Borderline (1.6\%) and 20 cases of Malignant (16.5\%). Similarly, study by Vijay Kumar Bodal et al showed $75 \%$ were benign; $1.66 \%$ Borderline and $23.3 \%$ malignant ${ }^{(12)}$.

In our study, there were 111 cases $(76.55 \%)$ of surface tumours , 31 cases $(21.38 \%)$ germ cell, 1 case $(0.69 \%)$ of sex cord, 2 cases $(1.38 \%)$ of metastatic ovarian tumours. In study by Veena Saxena, 60 cases $(70.83 \%)$ were surface tumours, 28 cases $(26.04 \%)$ germ cell, 3 cases $(3.13 \%)$ of sex cord tumours. In the study by Geetha Pachori, the most common ovarian tumors were surface epithelial tumors $(65.29 \%)$, followed by germ cell tumors $(23.97 \%)$ and sex cord-stromal tumors $(7.44 \%)(13,14)$.

In our study ,there were 96 cases of Serous cyst adenoma (66.21\%) , 4 cases of Mature cystic Teratoma , 1 case of Serous cyst adenofibroma $(0.69 \%), 1$ case of Teratoma with Struma ovarii $(0.69 \%)$. In study by Veena Saxena, commonest benign tumor studied were Serous cyst adenoma 57 cases $(57.8 \%)$ followed by Mature cystic teratoma 28 cases $(22.5 \%)$. Similarly, study by Dravid N.V et al showed most common lesion was serous cyst adenoma followed by Mature cystic Teratoma $(15,16)$.

In our study, there were 12 cases $(63.16 \%)$ of Serous cyst adenocarcinoma , 3 cases $(15.79 \%)$ of Immature teratoma, 2 cases of $(10.53 \%)$ Mucinoius cyst adenocarcinaoma , 1 case (5.26 $\%)$ of Krukenberg tumour and Granulosa cell tumour each .In study by Veena Saxena, there were 10 cases $(52.7 \%)$ of Serous cyst adenocarcinoma followed by $3(12.5 \%)$ cases of Mucinous cyst adenocarcinoma, 2 case $(10.5 \%)$ of Granulosa cell tumor, 1 case $(6.5 \%)$ of Dysgerminoma and 1 case $(6.25 \%)$ of Krukenbergtumor. 
In the present study, the most common specimen (as treatment modality) in malignant tumors was $\mathrm{TAH}+\mathrm{BSO}$. In benign and borderline tumors fertility preserving surgery in the form of cystectomy, unilateral salpingo-oophorectomy and oophorectomy were most common surgeries.

Ovarian tumors exhibited the wide spectrum of clinical and histological features. Ovarian malignancies are the second most common cancer among all cancers in the female genital tract. SETs were the most common followed by germ cell tumors. Borderline tumors were encountered more in the mucinous category than serous. Anorexia, ascites, and weight loss were associated with malignant tumors. On grossing presence of solid element makes malignancy more likely. The size of the tumor was not related to the nature of the tumor. In the era of immunohistochemistry and molecular pathology, where the diagnosis is based on these, in the institutes with limited resources, these clinicomorphological features are very helpful for diagnosis and proper management of the patients.

\section{CONCLUSION}

Serous cyst adenoma are the most common benign ovarian tumour found in ovarian specimens with peak incidence at $20-50$ years.

\section{Limitation of the study}

Status of Tumour markers were not studied

\section{Ethical committee approval}

Taken

\section{Financial support and sponsorship}

Nil

\section{Conflicts of interest}

There are no conflicts of interest

\section{BIBILOGRAPHY}

1. Morrison J. Advances in the understanding and treatment of ovarian cancer. $\mathrm{J} \mathrm{Br}$ Menopause Soc, 2005; 11: 66-71.

2. Gupta N, Bisht D, Agarwal AK, Sharma VK. Retrospective and prospective study of ovarian tumors and tumor like lesions. Indian J Pathol Microbiol 2007; 50: 525-7.

3. Rieber A, Nussle K. Preoperative diagnosis of ovarian tumors with MR imaging, comparison with transvaginal sonography, positron emission tomography and histological findings. AJR Am J Roentgenol 2001; 177: 123-9.

4. Sen U, Sankaranarayanan R, Mandal S, Romana AV, Parkin DM, Siddique M. Cancer patterns in Eastern India. The first report of Kolkata Cancer Registy. Int'1 J Cancer 2002; 100: 86-91

5. Layla. S.Abdulla, Nabeel S. Bondagji Histopathological pattern of ovarian neoplasms and their age distribution in the western region of Saudi Arabia, Saudi Med J 2012; Vol 33(1) 61-65.

6. Pilli GS, Suneeta KP, Dhaded AV, Yenni VV. Ovarian tumors: a study of 282 cases J Indian Med Assoc 2002; 100: 423-4.

7. S.M.TAMASKAR Ovarian sex-cord stromal tumors:"Newly Recognised Entities" Vol.2 (1), Jan.2009

8. Ahmad M, Malik TM, Afzal S, Mubarik A. Clinicopathological study of 762 ovarian neoplasms at Army Medical College Rawalpindi. Pak J Pathol 2004; 15 (4): 147-52.

9. Cook J. Family history of ovarian cancer. Current Obstetrics Gynaecology. 2002; 12:47-51

10. Sen U, Sankaranarayanan R, Mandal S, Romana AV, Parkin DM, Siddique M. Cancer patterns in Eastern India. The first report of Kolkata Cancer Registy. Int'1 J Cancer 2002; 100: 86-91.

11. Vijay Kumar Bodal,TanuJindal,Manajit Singh, Rajeev Bhagat,Sarabjeetkaur, Ninder Mall, Ankit Goel and Priyanka Goyal, A clinicopathological study of ovarian lesions. Vol.13 Issue (Supplementary One) 2014.

12. Haroon S, Zia A, Idrees R, Memon A, Fatima S, Kayani N. Clinicopathological 
spectrum of ovarian sex cord-stromal tumors; 20 years' retrospective study in a developing country. J Ovarian Res 2013;6:87.

13. Przybycin CG, Kurman RJ, Ronnett BM, Shih IeM, Vang R. Are all pelvic (nonuterine) serous carcinomas of tubal origin? Am J SurgPathol 2010;34:1407-16

14. La Vecchia C. Epidemiology of ovarian cancer: A summary review. Eur J Cancer Prev 2001;10:125-9.

15. Jemal A, Siegel R, Ward E, Hao Y, Xu J, Thun MJ. Cancer statistics, 2009. CA Cancer J Clin 2009;59:225-49.

16. Haroon S, Zia A, Idrees R, Memon A, Fatima S, Kayani N. Clinicopathological spectrum of ovarian sex cord-stromal tumors; 20 years' retrospective study in a developing country. J Ovarian Res 2013;6:87. 